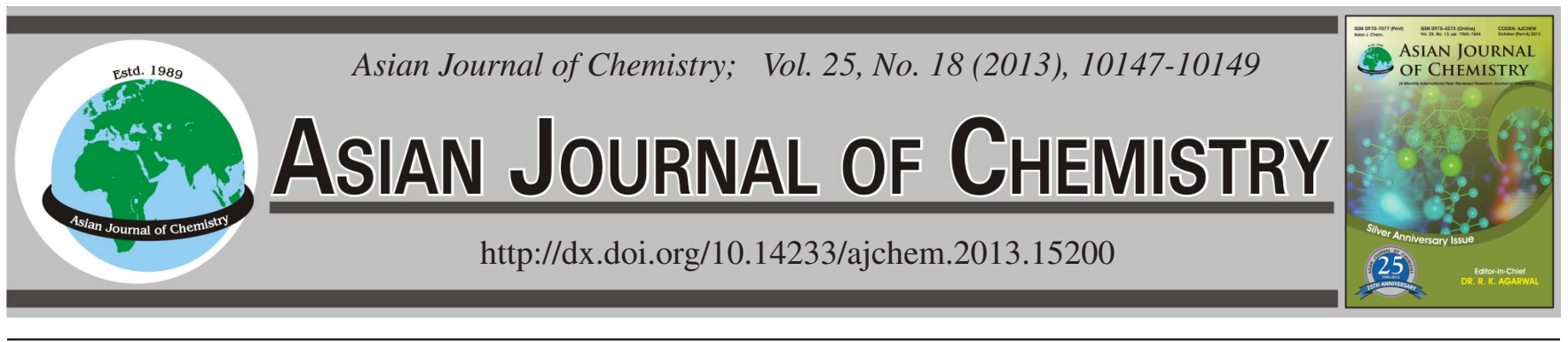

\title{
Electrochemical Sensor Based on Multi-Walled Carbon Nanotubes/ Gold Nanoparticles Composite for Determination of Melamine
}

\author{
JiAnYING Qu*, XuePIng Du, ShiPING Kang and Tongfang Lou
}

Institute of Environmental and Analytical Sciences, College of Chemistry and Chemical Engineering, Henan University, Kaifeng 475004, Henan Province, P.R. China

*Corresponding author: Fax: +86 378 3881589; E-mail: qjy405407@163.com

(Received: 25 January 2013;

Accepted: 11 November 2013)

AJC-14352

\begin{abstract}
A new electrochemical sensor was prepared based on multi-walled carbon nanotubes/gold nanoparticles and Nafion composite film immobilized on glassy carbon electrode, which showed an excellent electrocatalytic activity for oxidation of melamine. Under optimal conditions, the oxidation peak current was found to be linearly related to melamine concentration over the range of $3.9 \times 10^{-6}-4.0 \times 10^{-3}$ $\mathrm{mol} / \mathrm{L}$ with a detection limit of $1.9 \times 10^{-6} \mathrm{~mol} / \mathrm{L}$ and the recovery ratio was $94.6-101 \%$. This method for determination of melamine exhibited good stability, reproducibility and with easy preparation, which showed potential applications for practice.
\end{abstract}

Key Words: Multi-walled carbon nanotubes, Gold nanoparticles, Nafion, Melamine.

\section{INTRODUCTION}

Melamine, also known as protein fine, is an organic base with the chemical formula $\mathrm{C}_{3} \mathrm{H}_{6} \mathrm{~N}_{6}$, with the IUPAC name $1,3,5$ triazine-2,4,6-triamine. It is mainly used in the production of melamine-formaldehyde resin, widely used in the production of something like coatings, fabrics, paper-making, etc. ${ }^{1}$. Due to the content of nitrogen can be as high as $66.67 \%$, some illegal pedlars add it into the food product in order to give the false appearance of a higher level of protein than the true value $^{2,3}$. Melamine itself is slightly toxic, have adverse effect on the kidney and bladder as a result of being kidney stones, or even bladder cancer would induced by inhaled or absorbed for a long time ${ }^{4}$. Therefore, simple and sensitive methods of determining trace amounts of melamine are needed to deal with these problems. Many methods have been developed in recent years, for example, high-performance liquid chromatography ${ }^{5,6}$, gas or liquid chromatography-mass spectrometry ${ }^{7,8}$, enzyme-linked immunosorbent assay ${ }^{9}$, capillary electrophoresis ${ }^{10}$, electrochemical method ${ }^{11-13}$, etc. Compared with the other methods, electrochemical method has the characteristics of simplicity, low cost, accuracy, sensitivity and high stability.

Multiwalled carbon nanotubes (MWCNTs) have obtained considerable attention because of their unique physical, chemical and electrical property, large specific surface area, subtle electronic properties and have catalytic activity ${ }^{14,15}$. Gold nanoparticles (AuNPs) have attracted much attention because of its easy preparation, good biocompatibility and relatively large specific surface area, etc. ${ }^{16,17}$. Multiwalled carbon nanotubes and gold nanoparticles composite have both their advantage, especially the construction of the sensor has draw the attention of the scientific researchers. In addition, Nafion is a good cation exchange agent, it shows good exchange properties which is usually used as electron transfer.

In this study, a novel electrochemical sensor for the determination of melamine was introduced, which was constructed by Nafion/MWCNTs-AuNPs composite film modified glassy carbon electrode. The modified electrode showed an excellent catalytic behaviour for the oxidation of melamine and can be used to detect melamine.

\section{EXPERIMENTAL}

Electrochemical experiments were performed with a CHI650 electrochemical workstation (USA, CHI). A conventional three-electrode system was used where glassy carbon (GC) (3 mm diameter) or chemically modified GC electrodes, rotating platinum wire electrode and a $\mathrm{Ag} / \mathrm{AgCl}$ (saturated $\mathrm{KCl}$ ) were used as working, counter and reference electrodes, respectively. All potentials in this work referred to this reference electrode.

A stock standard solution of melamine was prepared in $\mathrm{HCl}(0.1 \mathrm{~mol} / \mathrm{L})$ at a concentration of $7.9 \times 10^{-3} \mathrm{~mol} / \mathrm{L}$ and was stored in a refrigerator. MWCNTs (Diameter 10-15 nm, University of Marburg, Germany, Department of Chemistry, Materials Science Center), $\mathrm{HAuCl}_{4}(0.1 \%)$, Nafion $(0.5 \%$ ethanol solution, Fluka), $\mathrm{HCl}(38 \%)$, other reagents were of 
analytical grade and the experimental water were double distilled water.

General procedure: Gold nanoparticles were prepared according to the literature ${ }^{18}: 50 \mathrm{~mL}$ of $\mathrm{HAuCl}_{4}(0.01 \% \mathrm{w} / \mathrm{w})$ solution was heated to boiling under a reflux condenser and sufficiently stirred conditions, $1 \mathrm{~mL}$ of sodium citrate solution (1\%) was added quickly to the boiling $\mathrm{HAuCl}_{4}$ with stirring. After that, the mixture was stirred for $0.5 \mathrm{~h}$ until the colour of the mixture changed from brown to wine red and then stopped heating. The stirring was continued until the temperature of the mixture decreased back to room temperature to get AuNPs, which were stored in a refrigerator.

The GC electrode was polished with 1.0, 0.3 and $0.05 \mu \mathrm{m}$ alumina slurry, then rinsed ultrasonically with $1: 1$ nitric acid solution, ethanol and doubly distilled water, respectively and dried in air. $2 \mathrm{mg}$ of MWNTs was dispersed in $2 \mathrm{~mL}$ of N,Ndimethyl-formamide by using ultrasonic agitation, then added in $2 \mathrm{~mL}$ of AuNPs glue solution to obtain MWCNTs-AuNPs suspension. $6 \mu \mathrm{L}$ of the MWCNTs-AuNPs suspension was dropped on the surface of GC electrode and dried in an infrared lamp to give a MWCNTs-AuNPs/GC electrode. Then, $5 \mu \mathrm{L}$ of Nafion solution ( $0.5 \%$ in ethol) was dripped onto the MWCNTs-AuNPs film, a Nafion/MWCNTs-AuNPs/GC electrode was obtained.

Detection method: Electrochemical measurements were performed on a CHI650 electrochemistry workstation with a conventional three-electrode system mentioned above. Scan range of electrochemical test is $0-1.5 \mathrm{~V}$, with the scan rate of $100 \mathrm{mV} / \mathrm{s}$. All experiments were carried out at room temperature.

\section{RESULTS AND DISCUSSION}

Electrocatalytic activity for melamine of the modified electrode: As shown in Fig. 1, the electrochemical behaviour of melamine at bare GC (curve a), AuNPs/GC (curve b), Nafion/GC (curve c), MWCNTs/GC (curve d), MWCNTsAuNPs/GC (curve e), Nafion/MWCNTs-AuNPs/GC (curve f) electrode were investigated by circulation voltammograms (CV). In melamine solution, no obvious peak was found at the bare GC and AuNPs/GC, but a couple redox peaks were found at Nafion/GC at about $0.85 \mathrm{~V}$ and $0.62 \mathrm{~V}$. Comparing this, besides a couple redox peaks of MWCNTs at about $0.4 \mathrm{~V}$, another couple redox peaks appeared at MWCNTs/GC $(0.65 \mathrm{~V}$ and $0.55 \mathrm{~V})$, MWCNTs-AuNPs/GC (0.7 and $0.6 \mathrm{~V})$ and Nafion/MWCNTs-AuNPs/GC (0.74 and $0.63 \mathrm{~V})$. The oxidation peak current is maximum at Nafion/MWCNTs-AuNPs/ GC, which demonstrates that this composite film possess good electro-catalytic activity to melamine. A single oxidation peak of melamine appeared at $0.7 \mathrm{~V}$, indicating an irreversible electro-chemical process (curve $g$ and $f$ ).

\section{Optimization of experimental conditions}

Influence of base solution and its concentration: Experiment showed that $\mathrm{HCl}$ was the optimal base solution for this study. And under the same conditions, influence of the concentration of $\mathrm{HCl}$ on the oxidation peak current at Nafion/MWCNTs-AuNPs/GC electrode was investigated too. Results showed that the oxidation current of melamine is higher at $0.1 \mathrm{~mol} / \mathrm{L} \mathrm{HCl}$. Therefore, $0.1 \mathrm{~mol} / \mathrm{L} \mathrm{HCl}$ was used as base solution for the experiments.
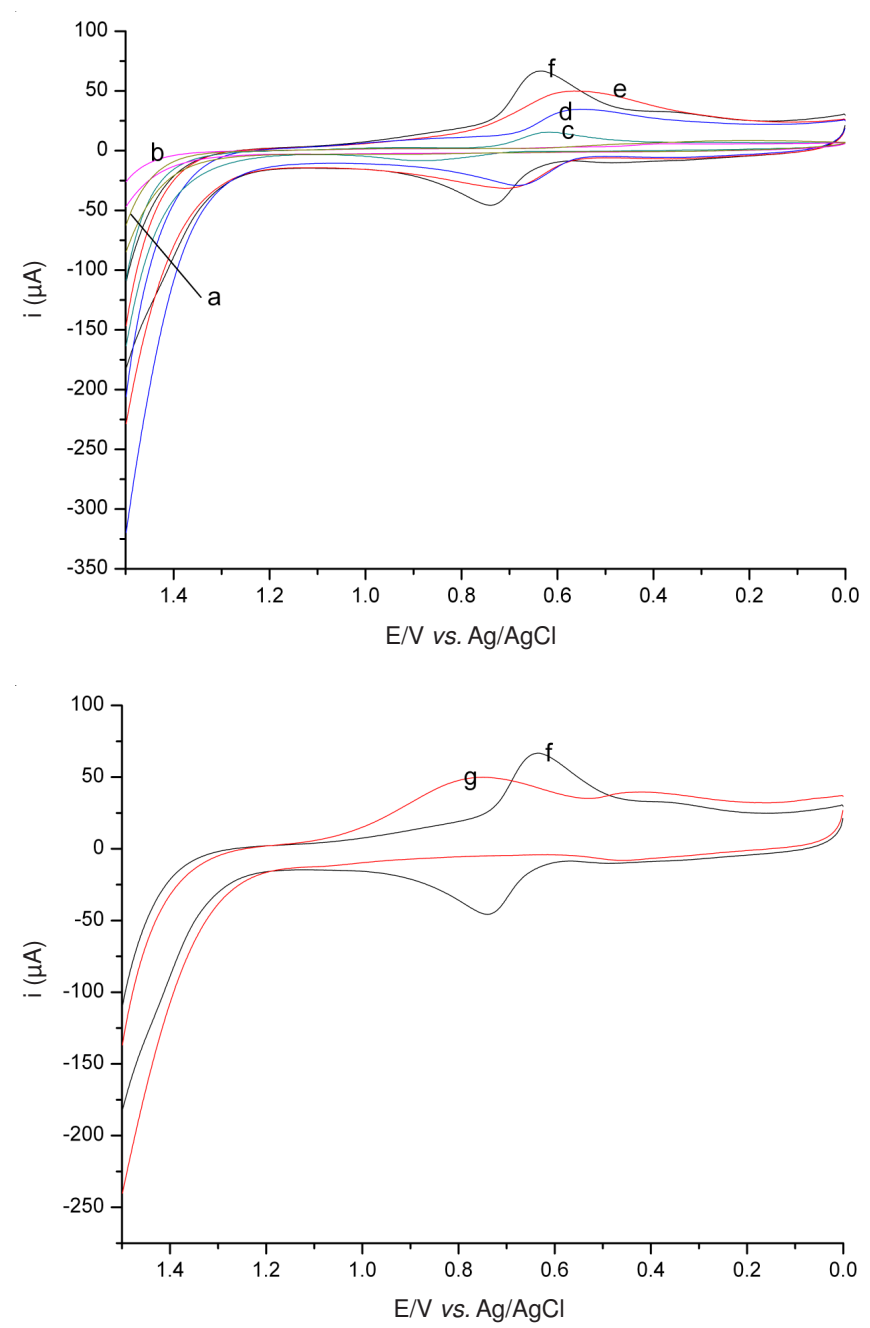

Fig. 1. CVs at bare GC (a), AuNPs/GC (b), Nafion/GC (c), MWCNTs/GC (d), MWCNTs-AuNPs/GC (e), Nafion/MWCNTs-AuNPs/GC (f) in $1.85 \times 10^{-3} \mathrm{~mol} / \mathrm{L}$ melamine $+0.1 \mathrm{~mol} / \mathrm{L} \mathrm{HCl}$ and Nafion/MWCNTsAuNPs/GC (g) electrode in $0.1 \mathrm{~mol} / \mathrm{L} \mathrm{HCl}$

Influence of MWCNTs-AuNPs film thickness: Influence of the film thickness of the MWCNTs-AuNPs composite on the melamine oxidation was studied. Experiments showed that with improving the amount of MWCNTs-AuNPs suspension from 2 to $6 \mu \mathrm{L}$, the oxidation peak currents of melamine enhanced remarkably. And when $6 \mu \mathrm{L}$ MWCNTs-AuNPs suspensions were used, the oxidation peak current can reach its maximum value. Increasing the amount of MWCNTsAuNPs suspension from 6 to $12 \mu \mathrm{L}$, the oxidation peak currents of melamine changed slightly. So, $6 \mu \mathrm{L}$ MWCNTs-AuNPs suspension was chosen to prepare the sensor.

Influence of scan rate: Influence of scan rate on the oxidation of melamine at Nafion/MWCNTs-AuNPs/GC electrode was investigated in the range of $20-300 \mathrm{mV} / \mathrm{s}$ for $1.85 \times$ $10^{-3} \mathrm{~mol} / \mathrm{L}$ melamine by linear sweep voltammetry (Fig. 2 ). It is clear that with increase of scan rate, the oxidation peak current increases and, the oxidation current was found to be linear to square root of scan rate (Fig. 2). The linear regression equation is $I_{p}(\mu \mathrm{A})=-4.0058+4.41767 v^{1 / 2}(R=0.9985)$, suggesting that this electrochemical process is diffusion-controlled.

Calibration curve: Under the optimal conditions, the relationship between the oxidation peak current and the melamine concentration give a good linear from $3.9 \times 10^{-6}$ to 


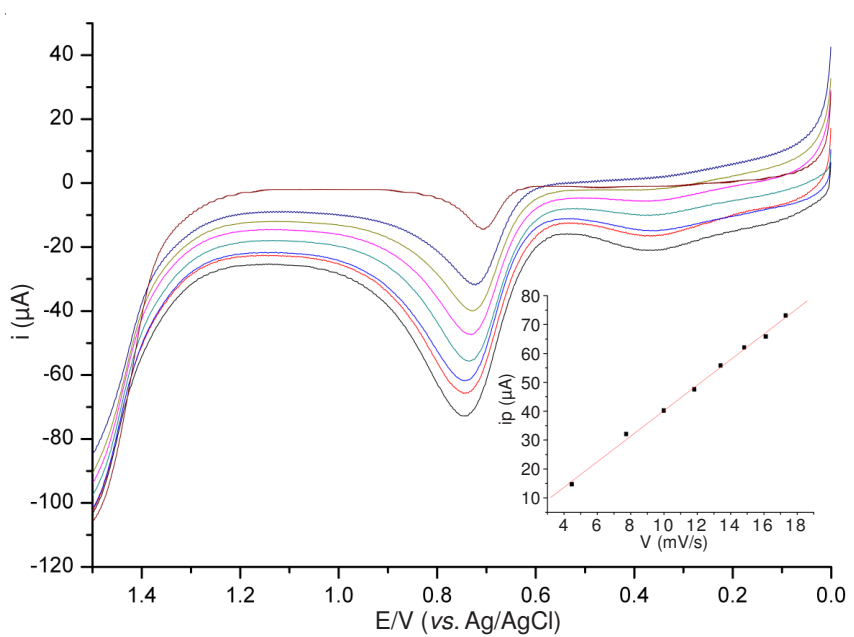

Fig. 2. CVs of Nafion/MWCNTs-AuNPs/GC electrode at different scan rates (from inner to outer: $20-230 \mathrm{mV} / \mathrm{s}$, respectively) in $1.85 \times 10^{-}$ ${ }^{3} \mathrm{~mol} / \mathrm{L}$ melamine $(0.1 \mathrm{~mol} / \mathrm{L} \mathrm{HCl})$, inset chart: The relationship between reduction peak current and scan rate

$4.0 \times 10^{-3} \mathrm{~mol} / \mathrm{L}($ Fig 3$)$. The regression equation is $\mathrm{I}_{\mathrm{p}}(\mu \mathrm{A})=$ $13.51+13.67961 \mathrm{c}(\mathrm{mmol} / \mathrm{L})(\mathrm{R}=0.9988)$ with the detection limit of $2.0 \times 10^{-6} \mathrm{~mol} / \mathrm{L}$.

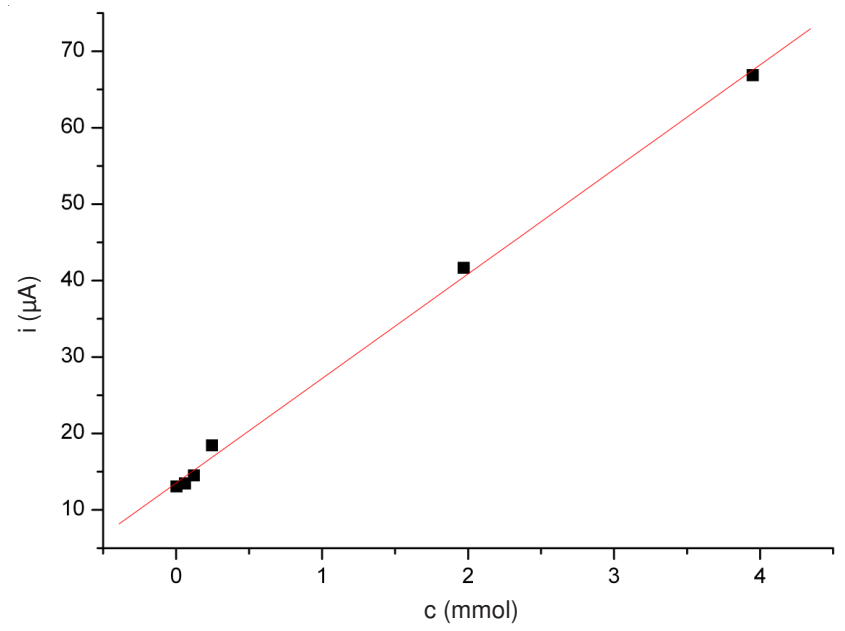

Fig. 3. Standard curve for different concentration of folic acid at Nafion/ MWCNTs-AuNPs/GC electrode in $1.85 \times 10^{-3} \mathrm{~mol} / \mathrm{L}$ melamine $(0.1$ $\mathrm{mol} / \mathrm{L} \mathrm{HCl}$ )

Recovery test: Under the optimal conditions, the Nafion/ MWCNTs-AuNPs/GC electrode was used for the detection of melamine in $0.1 \mathrm{~mol} / \mathrm{L} \mathrm{HCl}$. According to the blank standard addition method, we added different concentrations of melamine to the electrolytic cell, then determined their peak current and calculated their recoveries. Table- 1 showed the recovery of melamine was $94.6-101 \%$ and the average recovery of melamine was $97 \%$. It shows that the proposed method can be efficiently used for determination of melamine.

Interference studies: Under the same conditions, the influences of some inorganic ions, glucose, lysine, citric acid on the determination of the oxidation peak current of melamine were investigated. Experimental results showed that 500-fold of $\mathrm{Na}^{+}, \mathrm{Cl}^{-}, \mathrm{Ca}^{2+}, \mathrm{NO}_{3}^{-}, 300$-fold of $\mathrm{Zn}^{2+}, \mathrm{CH}_{3} \mathrm{COO}^{-}, 200$-fold of glucose, lysine, citric acid, 100-fold of $\mathrm{Mg}^{2+}$ almost have
TABLE-1

RESULTS OF TEST FOR RECOVERY RATIO

\begin{tabular}{cccc}
\hline $\begin{array}{c}\text { Added } \\
\left(\times 10^{-5} \mathrm{~mol} / \mathrm{L}\right)\end{array}$ & $\begin{array}{c}\text { Determined } \\
\left(\times 10^{-5} \mathrm{~mol} / \mathrm{L}\right)\end{array}$ & $\begin{array}{c}\text { Recovery } \\
(\%)\end{array}$ & $\begin{array}{c}\text { Average } \\
(\%)\end{array}$ \\
\hline 4.44 & 4.24 & 95.5 & \\
98.7 & 93.4 & 94.6 & 97.0 \\
185 & 186.8 & 101 & \\
\hline
\end{tabular}

no interference on determination of melamine. This demonstrated that the proposed method showed a good selectivity for detection of melamine.

Stability and reproducibility: The relative standard deviation for eight successive determinations is $1.2 \%$ in 1.85 $\times 10^{-3} \mathrm{~mol} / \mathrm{L}$ melamine solution This results indicate that the modified electrode shows good reproducibility.

The modified electrode was used to determination by continuous CV for 10 cycles, the oxidation peak current remained almost the same, which demonstrated that the modified electrode has a good stability.

\section{Conclusion}

In this work, based on MWCNTs-AuNPs and Nafion composite, a new electrochemical sensor for detection of melamine was prepared. The electrochemical process of melamine at this electrode is diffusion-controlled. The oxidation peak current of melamine changed linearly with its concentration in the range from $3.9 \times 10^{-6}$ to $4.0 \times 10^{-3} \mathrm{~mol} / \mathrm{L}$ with a correlation coefficient of 0.9988 . This method exhibited easy preparation, good reproducibility and stability.

\section{REFERENCES}

1. Ü.T. Yilmaz and Z. Yazar, Food Anal. Methods, 5, 119 (2012).

2. Y.T. Liu, J. Deng, X.L. Xiao, L. Ding, Y.L. Yuan, H. Li, X.T. Li, X.N. Yan and L.L. Wang, Electrochim. Acta, 56, 4595 (2011).

3. J.S. Chen, Chin. Med. J., 122, 243 (2009).

4. M.S. Filigenzi, B. Puschner, L.S. Aston and R.H. Poppenga, J. Agric. Food Chem., 56, 7593 (2008).

5. E.Y. Chan, S.M. Griffiths and C.W. Chan, Lancet, 372, 1444 (2008).

6. B. Kim, L.B. Perkins, R.J. Bushway, S. Nesbit, T.T. Fan, R. Sheridan and V. Greene, J. AOAC Int., 91, 408 (2008).

7. A. Desmarchelier, M. Cuadra, T. Delatour and P. Mottier, J. Agric. Food Chem., 57, 7186 (2009).

8. M. Ibanez, J.V. Sancho and F. Hernandez, Anal. Chim. Acta, 649, 91 (2009).

9. J. Liu, Y. Zhong, J. Liu, H. Zhang, J. Xi and J. Wang, Food Control, 21, 1482 (2010).

10. S.A. Tittlemier, Food Addit. Contam. A, 27, 129 (2010).

11. Q. Cao, H. Zhao, L. Zeng, J. Wang, R. Wang, X. Qiu and Y. He, Talanta, 80, 484 (2009).

12. R. Liang, R. Zhang and W. Qin, Sens. Actuators B, 141, 544 (2009).

13. J. Li, Z. Chen and Y. Li, Anal. Chim. Acta, 706, 255 (2011).

14. J.M. Nugent, K.S.V. Santhanam, A. Rubio and P.M. Ajayan, Nano Lett., 1, 87 (2001).

15. J.J. Davis, R.J. Coles, H. Allen and O. Hill, Electroanal. Chem., 440, 279 (1997).

16. W.P. McConnell, J.P. Novak, L.C. Brousseau, R.R. Fuierer, R.C. Tenent and D.L. Feldheim, J. Phys. Chem. B, 104, 8925 (2000).

17. A.C. Templeton, W.P. Wuelng and R.W. Murray, Acc. Chem Res., 33, 27 (2000).

18. G. Frens, Nat. Phys. Sci., 241, 20 (1973). 